\title{
KERNELS OF MORPHISMS BETWEEN INDECOMPOSABLE INJECTIVE MODULES
}

\author{
ALBERTO FACCHINI \\ Dipartimento di Matematica Pura e Applicata, Università di Padova, 35131 Padova, Italy \\ e-mail:facchini@math.unipd.it \\ ŞULE ECEVIT and M. TAMER KOŞAN \\ Department of Mathematics, Gebze Institute of Technology, Çayirova Campus, 41400 Gebze-Kocaeli, Turkey \\ e-mail: \{secevit,mtkosan\}@gyte.edu.tr
}

\begin{abstract}
We show that the endomorphism rings of kernels $\operatorname{ker} \varphi$ of non-injective morphisms $\varphi$ between indecomposable injective modules are either local or have two maximal ideals, the module $\operatorname{ker} \varphi$ is determined up to isomorphism by two invariants called monogeny class and upper part, and a weak form of the Krull-Schmidt theorem holds for direct sums of these kernels. We prove with an example that our pathological decompositions actually take place. We show that a direct sum of $n$ kernels of morphisms between injective indecomposable modules can have exactly $n$ ! pairwise non-isomorphic direct-sum decompositions into kernels of morphisms of the same type. If $E_{R}$ is an injective indecomposable module and $S$ is its endomorphism ring, the duality $\operatorname{Hom}\left(-, E_{R}\right)$ transforms kernels of morphisms $E_{R} \rightarrow E_{R}$ into cyclically presented left modules over the local ring $S$, sending the monogeny class into the epigeny class and the upper part into the lower part.
\end{abstract}

2000 Mathematics Subject Classification. 15A33.

1. Introduction. In 1996, the first author described the behaviour, as far as direct sums are concerned, of modules $M_{R}$ of Goldie dimension one and dual Goldie dimension one [4]. The endomorphism rings of these modules $M_{R}$ are either local or have two maximal ideals, the module $M_{R}$ is determined up to isomorphism by two invariants called monogeny class and epigeny class, and a weak form of the KrullSchmidt theorem holds for direct sums of these modules. In 2008 it was discovered [2] that a second class of modules has exactly the same behaviour. It is the class of cyclically presented modules over a local ring. The endomorphism ring of a cyclically presented module $N_{R}$ over a local ring $R$ is either local or has two maximal ideals, the module $N_{R}$ is determined up to isomorphism by its epigeny class and another invariant, called lower part, and a weak form of the Krull-Schmidt theorem holds for direct sums of these modules as well.

In this paper, we present a third class of modules with the same behaviour. They are the kernels of morphisms $\varphi$ between indecomposable injective modules. The endomorphism ring of such a $\operatorname{kernel} \operatorname{ker} \varphi$ is either local or has two maximal ideals, the module $\operatorname{ker} \varphi$ is determined up to isomorphism by its monogeny class and a second invariant, called upper part, and a weak form of the Krull-Schmidt theorem similar to that of the previous two classes also holds for direct sums of these kernels (Theorem 2.7). 
We then prove with an example that our pathological decompositions actually take place. We show that a direct sum of $n$ kernels of morphisms between injective indecomposable modules can have exactly $n$ ! pairwise non-isomorphic direct-sum decompositions into kernels of morphisms of the same type.

Finally, we show the relation between the class of modules studied in this paper and the cyclically presented modules over local rings studied in [2]. If $E_{R}$ is an injective indecomposable module and $S$ is its endomorphism ring, the duality $\operatorname{Hom}\left(-, E_{R}\right)$ transforms kernels of morphisms $E_{R} \rightarrow E_{R}$ into co-cyclically presented left modules over the local ring $S$, sending the monogeny class into the epigeny class and the upper part into the lower part.

2. The endomorphism ring. We fix the notation that will be used throughout the paper. All rings will be associative rings with identity, modules will be unital right modules and $E\left(M_{R}\right)$ will denote the injective envelope of a module $M_{R}$. Let $E_{1}, E_{2}, E_{1}^{\prime}, E_{2}^{\prime}$ be indecomposable injective right modules over an arbitrary ring $R$ and let $\varphi: E_{1} \rightarrow E_{2}, \varphi^{\prime}: E_{1}^{\prime} \rightarrow E_{2}^{\prime}$ be two non-injective morphisms. Any morphism $f: \operatorname{ker} \varphi \rightarrow \operatorname{ker} \varphi^{\prime}$ extends to a morphism $f_{1}: E_{1} \rightarrow E_{1}^{\prime}$, because $E_{1}$ and $E_{1}^{\prime}$ are injective modules containing $\operatorname{ker} \varphi, \operatorname{ker} \varphi^{\prime}$, respectively. Hence, $f_{1}$ induces a morphism $\widetilde{f}_{1}: E_{1} / \operatorname{ker} \varphi \rightarrow E_{1}^{\prime} / \operatorname{ker} \varphi^{\prime}$, which extends to a morphism $f_{2}: E_{2} \rightarrow E_{2}^{\prime}$. Thus, we have a commutative diagram with exact rows

$$
\begin{aligned}
& 0 \rightarrow \operatorname{ker} \varphi \rightarrow E_{1} \stackrel{\varphi}{\longrightarrow} E_{2} \\
& \downarrow f \quad \downarrow f_{1} \quad \downarrow f_{2} \\
& 0 \rightarrow \operatorname{ker} \varphi^{\prime} \rightarrow E_{1}^{\prime} \stackrel{\varphi^{\prime}}{\longrightarrow} E_{2}^{\prime} .
\end{aligned}
$$

Note that $f_{1}$ and $f_{2}$ are not uniquely determined by $f$. Nevertheless, assume that we have another commutative diagram

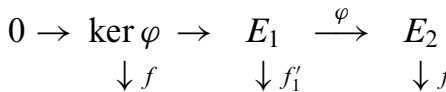

$$
\begin{aligned}
& 0 \rightarrow \operatorname{ker} \varphi^{\prime} \rightarrow E_{1}^{\prime} \stackrel{\varphi^{\prime}}{\longrightarrow} E_{2}^{\prime},
\end{aligned}
$$

for the same $f: \operatorname{ker} \varphi \rightarrow \operatorname{ker} \varphi^{\prime}$. We claim that, for $\varphi \neq 0$, both $f_{1}-f_{1}^{\prime}$ and $f_{2}-f_{2}^{\prime}$ have non-zero kernels. To prove the claim, note that $f_{1}-f_{1}^{\prime}$ is zero on $\operatorname{ker} \varphi$, so that $f_{1}-f_{1}^{\prime}$ has non-zero kernel. Moreover, $f_{1}-f_{1}^{\prime}$ induces a morphism $g: E_{1} / \operatorname{ker} \varphi \rightarrow E_{1}^{\prime}$, and there is a commutative diagram

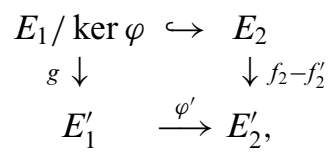

in which the upper arrow is injective. If $f_{2}-f_{2}^{\prime}$ is injective as well, then $\varphi^{\prime} g$ is injective, so that $\varphi^{\prime}$ is injective by [5, Lemma 6.26(a)]. This contradiction proves the claim. (Note that the proof of this claim is modelled on the proof of [6]. The most important sources of ideas for this paper have been [4] and [6].)

In our first result we consider the case in which $E_{1}=E_{1}^{\prime}, E_{2}=E_{2}^{\prime}$ and $\varphi_{1}=\varphi_{1}^{\prime}$.

THEOREM 2.1. Let $E_{1}$ and $E_{2}$ be two indecomposable injective right modules over an arbitrary ring $R$, and let $\varphi: E_{1} \rightarrow E_{2}$ be a non-zero non-injective morphism. Set 
$I:=\left\{f \in \operatorname{End}_{R}(\operatorname{ker} \varphi) \mid f\right.$ is not injective $\}=\left\{f \in \operatorname{End}_{R}(\operatorname{ker} \varphi) \mid f_{1}\right.$ is not injective $\}$ and $K:=\left\{f \in \operatorname{End}_{R}(\operatorname{ker} \varphi) \mid f_{2}\right.$ is not injective $\}=\left\{f \in \operatorname{End}_{R}(\operatorname{ker} \varphi) \mid f_{1}^{-1}(\operatorname{ker} \varphi) \supsetneqq\right.$ $\operatorname{ker} \varphi\}$. Then $I$ and $K$ are two completely prime two-sided ideals of $\operatorname{End}_{R}(\operatorname{ker} \varphi)$, and every proper right or left ideal of $\operatorname{End}_{R}(\operatorname{ker} \varphi)$ is contained in either I or K. Moreover, exactly one of the following two cases holds:

(a) either the ideals $I$ and $K$ are comparable, so that $\operatorname{End}_{R}(\operatorname{ker} \varphi)$ is a local ring, or

(b) the ideals $I$ and $K$ are not comparable, $J\left(\operatorname{End}_{R}(\operatorname{ker} \varphi)\right)=I \cap K$ and

$$
\operatorname{End}_{R}(\operatorname{ker} \varphi) / J\left(\operatorname{End}_{R}(\operatorname{ker} \varphi)\right)
$$

is canonically isomorphic to the direct product of the two division rings

$$
\operatorname{End}_{R}(\operatorname{ker} \varphi) / I \quad \text { and } \operatorname{End}_{R}(\operatorname{ker} \varphi) / K
$$

Proof. Consider the mapping $F_{1}: \operatorname{End}_{R}(\operatorname{ker} \varphi) \rightarrow \operatorname{End}_{R}\left(E_{1}\right) / J\left(\operatorname{End}_{R}\left(E_{1}\right)\right)$ defined by $F_{1}(f)=f_{1}+J\left(\operatorname{End}_{R}\left(E_{1}\right)\right)$ for every $f \in \operatorname{End}_{R}(\operatorname{ker} \varphi)$. Then $F_{1}$ is a ring morphism, $\operatorname{End}_{R}\left(E_{1}\right) / J\left(\operatorname{End}_{R}\left(E_{1}\right)\right)$ is a division ring and $I=\operatorname{ker}\left(F_{1}\right)$. Thus, $I$ is a completely prime two-sided ideal of $\operatorname{End}_{R}(\operatorname{ker} \varphi)$. Similarly, let $F_{2}: \operatorname{End}_{R}(\operatorname{ker} \varphi) \rightarrow$ $\operatorname{End}_{R}\left(E_{2}\right) / J\left(\operatorname{End}_{R}\left(E_{2}\right)\right)$ be defined by $F_{2}(f)=f_{2}+J\left(\operatorname{End}_{R}\left(E_{2}\right)\right)$ for every $f \in$ $\operatorname{End}_{R}(\operatorname{ker} \varphi)$. Then $F_{2}$ is a ring morphism, $\operatorname{End}_{R}\left(E_{2}\right) / J\left(\operatorname{End}_{R}\left(E_{2}\right)\right)$ is a division ring and $K=\operatorname{ker}\left(F_{2}\right)$. (The proof that $F_{1}$ and $F_{2}$ are well defined follows immediately from the claim before the statement of the theorem.) Therefore, $K$ is a completely prime two-sided ideal in $\operatorname{End}_{R}(\operatorname{ker} \varphi)$.

In particular, $I$ and $K$ are two proper ideals of $\operatorname{End}_{R}(\operatorname{ker} \varphi)$, so that all the elements of $I \cup K$ are non-invertible elements of $\operatorname{End}_{R}(\operatorname{ker} \varphi)$. Conversely, let $f \notin I \cup K$ be an element of $\operatorname{End}_{R}(\operatorname{ker} \varphi)$, so that there is a commutative diagram

$$
\begin{aligned}
& 0 \rightarrow \operatorname{ker} \varphi \rightarrow E_{1} \rightarrow E_{1} / \operatorname{ker} \varphi \rightarrow 0 \\
& f \downarrow \quad \downarrow f_{1} \quad \downarrow \widetilde{f_{1}} \\
& 0 \rightarrow \operatorname{ker} \varphi \rightarrow E_{1} \rightarrow E_{1} / \operatorname{ker} \varphi \rightarrow 0 \text {. }
\end{aligned}
$$

As $f \notin I$, the morphism $f$ must be injective, so that $f_{1}$ is injective. Thus, $f_{1}$ is an isomorphism, because $E_{1}$ is indecomposable. As $f \notin K$, we have that $\widetilde{f}_{1}$ is injective. By the Snake lemma, $f$ must be an isomorphism, so that $f$ is invertible in $\operatorname{End}_{R}(\operatorname{ker} \varphi)$. This shows that $I \cup K$ is exactly the set of all non-invertible elements of $\operatorname{End}_{R}(\operatorname{ker} \varphi)$.

Every proper right or left ideal $L$ of $\operatorname{End}_{R}(\operatorname{ker} \varphi)$ must be therefore contained in $I \cup K$. Let us prove that such an $L$ must be contained either in $I$ or in $K$. If this would not be true, there would exist $f \in L \backslash I$ and $g \in L \backslash K$. Then $f+g \in L, f \in K$ and $g \in I$. Hence, $f+g \notin I$ and $f+g \notin K$. Thus, $f+g \notin I \cup K$. But $f+g \in L$, which is a contradiction. This proves that $L$ is contained either in $I$ or in $K$. In particular, the unique maximal right ideals of $\operatorname{End}_{R}(\operatorname{ker} \varphi)$ are at most $I$ and $K$. Similarly, the unique maximal left ideals of $\operatorname{End}_{R}(\operatorname{ker} \varphi)$ are at most $I$ and $K$.

If $I$ and $K$ are comparable, then $I \cup K$ is the unique maximal right (and left) ideal of $\operatorname{End}_{R}(\operatorname{ker} \varphi)$ and statement (a) holds. If $I$ and $K$ are not comparable, then $\operatorname{End}_{R}(\operatorname{ker} \varphi)$ has exactly two maximal right ideals $I$ and $K$, so that $J\left(\operatorname{End}_{R}(\operatorname{ker} \varphi)\right)=I \cap K$, and there is a canonical injective ring homomorphism

$$
\pi: \operatorname{End}_{R}(\operatorname{ker} \varphi) / J\left(\operatorname{End}_{R}(\operatorname{ker} \varphi)\right) \rightarrow \operatorname{End}_{R}(\operatorname{ker} \varphi) / I \times \operatorname{End}_{R}(\operatorname{ker} \varphi) / K
$$


Now $I+K=\operatorname{End}_{R}(\operatorname{ker} \varphi)$, because $I$ and $K$ are incomparable maximal ideals. Hence, $\pi$ is surjective by the Chinese remainder theorem.

EXAMPLE 2.2. (1) Assume that the ring $R$ is a commutative local ring with maximal ideal $M$ and $\varphi: E_{1} \rightarrow E_{2}$ is a non-zero non-injective morphism between two indecomposable injective modules $E_{1}, E_{2}$. As $R$ is commutative, multiplication induces a ring morphism $\mu: R \rightarrow \operatorname{End}_{R}\left(E_{1}\right)$. Suppose that this morphism $\mu$ is onto, e.g. suppose that $R$ is a commutative, Noetherian, complete, local ring and $E_{1}=E(R / M)$ [8, Theorem 3.7]. Then $\operatorname{End}(\operatorname{ker} \varphi) \cong R / \operatorname{Ann}_{R}(\operatorname{ker} \varphi)$, where $A_{A n n}(\operatorname{ker} \varphi)$ denotes the annihilator of $\operatorname{ker} \varphi$. In the isomorphism $\operatorname{End}(\operatorname{ker} \varphi) \cong R / \operatorname{Ann}_{R}(\operatorname{ker} \varphi)$, the maximal ideal $J(\operatorname{End}(\operatorname{ker} \varphi))$ of $\operatorname{End}(\operatorname{ker} \varphi)$ corresponds to the maximal ideal $M / \operatorname{Ann}_{R}(\operatorname{ker} \varphi)$ of $R / \mathrm{Ann}_{R}(\operatorname{ker} \varphi)$. In the notation of Theorem 2.1, we have $I \supseteq K$ in this particular commutative case.

(2) Let $R$ be a commutative almost maximal valuation ring. In this case, the ring morphism $\mu: R \rightarrow \operatorname{End}_{R}\left(E_{1}\right)$ induced by multiplication is not necessarily onto, but every indecomposable injective module is uniserial by [7]. Hence, $\operatorname{ker} \varphi$ is always uniserial for such an $R$, so that $\operatorname{End}(\operatorname{ker} \varphi)$ is commutative and local by [9].

Lemma 2.3. Let $E_{1}, E_{2}, E_{1}^{\prime}, E_{2}^{\prime}$ be indecomposable injective $R$-modules, and let $\varphi: E_{1} \rightarrow E_{2}$ and $\varphi^{\prime}: E_{1}^{\prime} \rightarrow E_{2}^{\prime}$ be two non-injective morphisms. Then ker $\varphi \cong k e r \varphi^{\prime}$ if and only if either $\varphi=\varphi^{\prime}=0$ and $E_{1} \cong E_{1}^{\prime}$, or there exists a commutative diagram

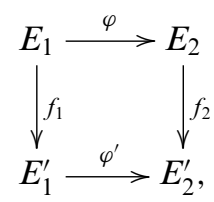

in which the vertical arrows are isomorphisms.

Proof. Assume that there exists an isomorphism $f: \operatorname{ker} \varphi \rightarrow \operatorname{ker} \varphi^{\prime}$. Then $f$ extends to an injective homomorphism $f_{1}: E_{1} \rightarrow E_{1}^{\prime}$, which is an isomorphism because $E_{1}^{\prime}$ is indecomposable. Hence, we have a commutative diagram with exact rows

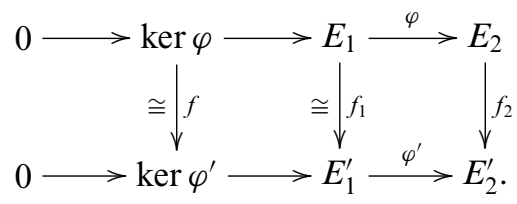

We have two possible cases:

(a) If $\varphi=0$, then $\operatorname{ker} \varphi=E_{1}$ and $\operatorname{ker} \varphi^{\prime}=E_{1}^{\prime}$. Hence, $E_{1} \cong E_{1}^{\prime}$ and $\varphi^{\prime}=0$.

(b) If $\varphi \neq 0$, then Diagram (2.1) induces a commutative diagram with exact rows

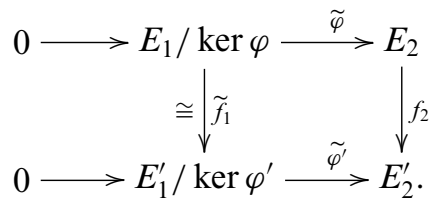

Now $E_{1} / \operatorname{ker} \varphi \neq 0$ implies that $f_{2}$ is injective. This and the fact that $E_{2}^{\prime}$ is indecomposable imply that $f_{2}$ is an isomorphism. The converse is trivial. 
Let $A$ and $B$ be two modules. We say that

- $A$ and $B$ have the same monogeny class, and write $[A]_{m}=[B]_{m}$, if there exist a monomorphism $A \rightarrow B$ and a monomorphism $B \rightarrow A[4]$;

- $A$ and $B$ have the same epigeny class, and write $[A]_{e}=[B]_{e}$, if there exist an epimorphism $A \rightarrow B$ and an epimorphism $B \rightarrow A$;

- $A$ and $B$ have the same upper part, and write $[A]_{u}=[B]_{u}$, if there exist a homomorphism $\varphi: E(A) \rightarrow E(B)$ and a homomorphism $\psi: E(B) \rightarrow E(A)$ such that $\varphi^{-1}(B)=A$ and $\psi^{-1}(A)=B$.

The motivation for the terminology 'having the same upper part' lies in the fact that if $[A]_{u}=[B]_{u}$, then $[E(A) / A]_{m}=[E(B) / B]_{m}$, so that $E(E(A) / A) \cong E(E(B) / B)$ by Bumby's theorem [3]. Moreover, we shall see in Proposition 4.1 that $\operatorname{ker} f$ and $\operatorname{ker} g$ have the same monogeny class if and only if the cyclically presented modules corresponding to $\operatorname{ker} f$ and ker $g$ via an exact contravariant functor have the same epigeny class, and $\operatorname{ker} f$ and $\operatorname{ker} g$ have the same upper part if and only if the modules corresponding to ker $f$ and ker $g$ via the same contravariant functor have the same lower part in the sense of [2]. Two cyclically presented modules $R / a R$ and $R / b R$ over a local ring $R$ are said to have the same lower part, denoted by $[R / a R]_{l}=[R / b R]_{l}$, if there exist $r, s \in R$ such that $r a R=b R$ and $s b R=a R[2]$.

It is clear that a module $A$ has the same monogeny (epigeny) class as the zero module if and only if $A=0$. We leave to the reader the verification of the easy fact that a module $A$ has the same upper part as the zero module if and only if $A$ is an injective module.

LeMmA 2.4. Let $E_{1}, E_{2}, E_{1}^{\prime}, E_{2}^{\prime}$ be injective indecomposable right modules over an arbitrary ring $R$ and let $\varphi: E_{1} \rightarrow E_{2}, \varphi^{\prime}: E_{1}^{\prime} \rightarrow E_{2}^{\prime}$ be arbitrary morphisms. Then $\operatorname{ker} \varphi \cong$ $\operatorname{ker} \varphi^{\prime}$ if and only if $[\operatorname{ker} \varphi]_{m}=\left[\operatorname{ker} \varphi^{\prime}\right]_{m}$ and $[\operatorname{ker} \varphi]_{u}=\left[\operatorname{ker} \varphi^{\prime}\right]_{u}$.

Proof. Suppose that one of the two morphisms $\varphi, \varphi^{\prime}$ is injective, e.g. suppose $\varphi$ is injective. Then $\operatorname{ker} \varphi \cong \operatorname{ker} \varphi^{\prime}$ if and only if $\operatorname{ker} \varphi^{\prime}=0,[\operatorname{ker} \varphi]_{m}=\left[\operatorname{ker} \varphi^{\prime}\right]_{m}$ if and only if $\operatorname{ker} \varphi^{\prime}=0$, and $[\operatorname{ker} \varphi]_{u}=\left[\operatorname{ker} \varphi^{\prime}\right]_{u}$ if and only if $\operatorname{ker} \varphi^{\prime}$ is an injective module. Therefore, the lemma holds if one of the two morphisms $\varphi, \varphi^{\prime}$ is injective, and from now on we can suppose that both $\varphi$ and $\varphi^{\prime}$ are non-injective.

Assume that $[\operatorname{ker} \varphi]_{m}=\left[\operatorname{ker} \varphi^{\prime}\right]_{m}$ and $[\operatorname{ker} \varphi]_{u}=\left[\operatorname{ker} \varphi^{\prime}\right]_{u}$. Then there are a monomorphism $f: \operatorname{ker} \varphi \rightarrow \operatorname{ker} \varphi^{\prime}$ and a homomorphism $h_{1}: E_{1} \rightarrow E_{1}^{\prime}$ such that $h_{1}^{-1}\left(\operatorname{ker} \varphi^{\prime}\right)=\operatorname{ker} \varphi$. If $f$ is onto, then $f$ is an isomorphism between $\operatorname{ker} \varphi$ and $\operatorname{ker} \varphi^{\prime}$ and we are done. Hence, we can assume that the monomorphism $f$ is not onto. We have a commutative diagram

$$
\begin{aligned}
& 0 \rightarrow \operatorname{ker} \varphi \rightarrow E_{1} \rightarrow E_{1} / \operatorname{ker} \varphi \rightarrow 0 \\
& f \downarrow \quad \downarrow f_{1} \quad \downarrow \tilde{f}_{1} \\
& 0 \rightarrow \operatorname{ker} \varphi^{\prime} \rightarrow \quad E_{1}^{\prime} \rightarrow E_{1}^{\prime} / \operatorname{ker} \varphi^{\prime} \rightarrow 0 \text {. }
\end{aligned}
$$

Now $f$ monomorphism implies that $f_{1}$ is an isomorphism, so that $\operatorname{ker}\left(\tilde{f}_{1}\right) \cong \operatorname{coker}(f)$ by the Snake lemma. Thus, $\widetilde{f}_{1}$ is not injective. Hence, $f_{2}: E_{2} \rightarrow E_{2}^{\prime}$ is not injective.

From $h_{1}^{-1}\left(\operatorname{ker} \varphi^{\prime}\right)=\operatorname{ker} \varphi$, we know that $h_{1}(\operatorname{ker} \varphi) \subseteq \operatorname{ker} \varphi^{\prime}$, so that $h_{1}$ induces by restriction a morphism $h: \operatorname{ker} \varphi \rightarrow \operatorname{ker} \varphi^{\prime}$. We have a commutative diagram

$$
\begin{aligned}
& 0 \rightarrow \operatorname{ker} \varphi \rightarrow E_{1} \rightarrow E_{1} / \operatorname{ker} \varphi \rightarrow 0 \\
& h \downarrow \quad \downarrow h_{1} \quad \downarrow \widetilde{h_{1}} \\
& 0 \rightarrow \operatorname{ker} \varphi^{\prime} \rightarrow \quad E_{1}^{\prime} \rightarrow E_{1}^{\prime} / \operatorname{ker} \varphi^{\prime} \rightarrow 0 \text {. }
\end{aligned}
$$


As $h_{1}^{-1}\left(\operatorname{ker} \varphi^{\prime}\right)=\operatorname{ker} \varphi$, we know that $\tilde{h_{1}}$ is a monomorphism. If $h_{1}$ is an isomorphism, then $h$ is a monomorphism and the Snake lemma gives that $\operatorname{ker}\left(\widetilde{h_{1}}\right) \cong \operatorname{coker}(h)$. Hence, $h$ is onto, that is, $h$ is the required isomorphism between $\operatorname{ker} \varphi$ and $\operatorname{ker} \varphi^{\prime}$. Thus, we can assume that $h_{1}$ is not an isomorphism. Since $E_{1}, E_{1}^{\prime}$ are indecomposable and injective, we get that $h_{1}$ is not a monomorphism. Hence, $h$ is not a monomorphism. Consider the sum of the two previous commutative diagrams. We get a commutative diagram

$$
\begin{array}{rlrrrrr}
0 \rightarrow \quad \operatorname{ker} \varphi & \rightarrow & E_{1} & \rightarrow & E_{1} / \operatorname{ker} \varphi & \rightarrow 0 \\
& f+h \downarrow & & \downarrow f_{1}+h_{1} & & \downarrow \widetilde{f_{1}+\widetilde{h}_{1}} \\
0 \rightarrow \quad \operatorname{ker} \varphi^{\prime} & \rightarrow & E_{1}^{\prime} & \rightarrow & E_{1}^{\prime} / \operatorname{ker} \varphi^{\prime} & \rightarrow 0 .
\end{array}
$$

Now $f_{1}$ is an isomorphism and $h_{1}$ is not a monomorphism. Since the sum of two noninjective morphisms $E_{1} \rightarrow E_{1}^{\prime}$ is non-injective because $E_{1}$ is uniform, it follows that $f_{1}+h_{1}$ must be a monomorphism. As $E_{1}^{\prime}$ is indecomposable injective, the morphism $f_{1}+h_{1}$ must be an isomorphism. Thus, the restriction $f+h$ of $f_{1}+h_{1}$ to $\operatorname{ker} \varphi$ is a monomorphism. Similarly $\widetilde{f}_{1}$ not injective, $\widetilde{h_{1}}$ injective and $E_{1} / \operatorname{ker} \varphi \subseteq E_{2}$ uniform imply that $\widetilde{f_{1}}+\widetilde{\widetilde{h}}_{1}$ is injective. The Snake lemma gives that $f+h$ is onto. Hence, $f+h$ is the required isomorphism between $\operatorname{ker} \varphi$ and $\operatorname{ker} \varphi^{\prime}$.

Proposition 2.5. Let $\varphi_{i}: E_{i, 1} \rightarrow E_{i, 2}(i=1,2, \ldots, n, n \geq 2)$ and $\varphi^{\prime}: E_{1}^{\prime} \rightarrow E_{2}^{\prime}$ be $n+1$ non-injective morphisms between indecomposable injective modules $E_{i, 1}, E_{i, 2} E_{1}^{\prime}, E_{2}^{\prime}$. Suppose that $\operatorname{ker} \varphi^{\prime}$ is isomorphic to a direct summand of $\oplus_{i=1}^{n} \operatorname{ker} \varphi_{i}$, but $\operatorname{ker} \varphi^{\prime} \nsucceq \operatorname{ker} \varphi_{i}$ for every $i=1,2, \ldots, n$. Then there are two distinct indices $i, j=1,2, \ldots, n$ such that $\left[\operatorname{ker} \varphi^{\prime}\right]_{m}=\left[\operatorname{ker} \varphi_{i}\right]_{m}$ and $\left[\operatorname{ker} \varphi^{\prime}\right]_{u}=\left[\operatorname{ker} \varphi_{j}\right]_{u}$.

Proof. Since $\operatorname{ker} \varphi^{\prime}$ is isomorphic to a direct summand of $\oplus_{i=1}^{n} \operatorname{ker} \varphi$ and $\operatorname{ker} \varphi^{\prime} \not$ $\operatorname{ker} \varphi_{i}$ for every $i=1,2, \ldots, n$, it follows that $\operatorname{End}_{R}\left(\operatorname{ker} \varphi^{\prime}\right)$ is not local. Let $\varepsilon: \operatorname{ker} \varphi^{\prime} \rightarrow$ $\oplus_{i=1}^{n} \operatorname{ker} \varphi_{i}$ and $\pi: \oplus_{i=1}^{n} \operatorname{ker} \varphi_{i} \rightarrow \operatorname{ker} \varphi^{\prime}$ be morphisms with the composite mapping $\pi \varepsilon$ equal to the identity of $\operatorname{ker} \varphi^{\prime}$. There exist maps $\varepsilon_{i}: \operatorname{ker} \varphi^{\prime} \rightarrow \operatorname{ker} \varphi_{i}$ and $\pi_{i}: \operatorname{ker} \varphi_{i} \rightarrow$ $\operatorname{ker} \varphi^{\prime}(i=1,2, \ldots, n)$ with

$$
\varepsilon=\left(\begin{array}{c}
\varepsilon_{1} \\
\varepsilon_{2} \\
\vdots \\
\varepsilon_{n}
\end{array}\right)
$$

and $\pi=\left(\begin{array}{llll}\pi_{1} & \pi_{2} & \cdots & \pi_{n}\end{array}\right)$. Then $\sum_{i=1}^{n} \pi_{i} \varepsilon_{i}=1_{\operatorname{ker} \varphi^{\prime}}$, so that there is an index $i$ with $\pi_{i} \varepsilon_{i} \notin I$. Similarly, $\sum_{i=1}^{n} \pi_{i} \varepsilon_{i} \notin K$, so that there exists an index $j$ with $\pi_{j} \varepsilon_{j} \notin K$. From the hypothesis that $\operatorname{ker} \varphi^{\prime} \not \operatorname{ker} \varphi_{i}$, it is easily seen that $\pi_{j} \varepsilon_{j} \in I$ (otherwise $\pi_{i} \varepsilon_{i}$ would be an automorphism). In particular, $i \neq j$.

Now, $\pi_{i} \varepsilon_{i} \notin I$ implies that $\pi_{i} \varepsilon_{i}: \operatorname{ker} \varphi^{\prime} \rightarrow \operatorname{ker} \varphi^{\prime}$ is injective, so that $\varepsilon_{i}$ and $\pi_{i}$ are injective by [5, Lemma 6.26(a)]. Thus, $\left[\operatorname{ker} \varphi^{\prime}\right]_{m}=\left[\operatorname{ker} \varphi_{i}\right]_{m}$. 
Consider the commutative diagram

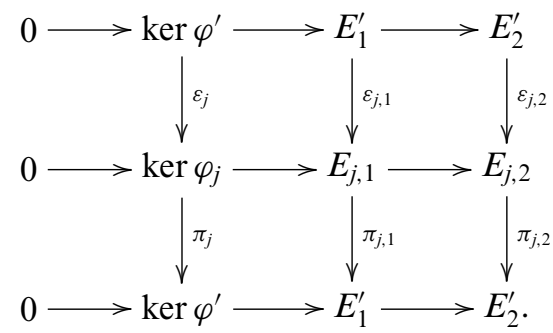

Then $\pi_{j} \varepsilon_{j} \notin K$ implies that $\pi_{j, 2} \varepsilon_{j, 2}$ is injective, so that $\pi_{j, 2}$ and $\varepsilon_{j, 2}$ are injective by [5, Lemma 6.26(a)]. Hence, $\widetilde{\varepsilon_{j, 1}}: E_{1}^{\prime} / \operatorname{ker} \varphi^{\prime} \rightarrow E_{j, 1} / \operatorname{ker} \varphi_{j}$ and $\widetilde{\pi_{j, 1}}: E_{j, 1} / \operatorname{ker} \varphi_{j} \rightarrow$ $E_{1}^{\prime} / \operatorname{ker} \varphi^{\prime}$ are injective, so that $\varepsilon_{j, 1}^{-1}\left(\operatorname{ker} \varphi_{j}\right)=\operatorname{ker} \varphi^{\prime}$ and $\pi_{j, 1}^{-1}\left(\operatorname{ker} \varphi^{\prime}\right)=\operatorname{ker} \varphi_{j}$. Thus, $\left[\operatorname{ker} \varphi^{\prime}\right]_{u}=\left[\operatorname{ker} \varphi_{j}\right]_{u}$.

Lemma 2.6. Let $\varphi: E_{1} \rightarrow E_{2}, \varphi^{\prime}: E_{1}^{\prime} \rightarrow E_{2}^{\prime}$ and $\varphi^{\prime \prime}: E_{1}^{\prime \prime} \rightarrow E_{2}^{\prime \prime}$ be non-injective morphisms between indecomposable injective modules. Assume $[\operatorname{ker} \varphi]_{m}=\left[\operatorname{ker} \varphi^{\prime}\right]_{m}$ and $[\operatorname{ker} \varphi]_{u}=\left[\operatorname{ker} \varphi^{\prime \prime}\right]_{u}$. Then, the following hold:

(a) $\operatorname{ker} \varphi \oplus D \cong \operatorname{ker} \varphi^{\prime} \oplus \operatorname{ker} \varphi^{\prime \prime}$ for some $R$-module $D$.

(b) The module D in (a) is unique up to isomorphism and is the kernel of a non-injective morphism between indecomposable injective modules.

(c) $[D]_{m}=\left[\operatorname{ker} \varphi^{\prime \prime}\right]_{m}$ and $[D]_{u}=\left[\operatorname{ker} \varphi^{\prime}\right]_{u}$.

Proof. (a) Since $[\operatorname{ker} \varphi]_{m}=\left[\operatorname{ker} \varphi^{\prime}\right]_{m}$ and $[\operatorname{ker} \varphi]_{u}=\left[\operatorname{ker} \varphi^{\prime \prime}\right]_{u}$ by assumption, we have that there exist monomorphisms $f: \operatorname{ker} \varphi \rightarrow \operatorname{ker} \varphi^{\prime}$ and $g: \operatorname{ker} \varphi^{\prime} \rightarrow \operatorname{ker} \varphi$, and homomorphisms $h_{1}: E(\operatorname{ker} \varphi) \rightarrow E\left(\operatorname{ker} \varphi^{\prime \prime}\right)$ and $l_{1}: E\left(\operatorname{ker} \varphi^{\prime \prime}\right) \rightarrow E(\operatorname{ker} \varphi)$ with $h_{1}^{-1}\left(\operatorname{ker} \varphi^{\prime \prime}\right)=\operatorname{ker} \varphi$ and $l_{1}^{-1}(\operatorname{ker} \varphi)=\operatorname{ker} \varphi^{\prime \prime}$. Let $h: \operatorname{ker} \varphi \rightarrow \operatorname{ker} \varphi^{\prime \prime}$ and $l: \operatorname{ker} \varphi^{\prime \prime} \rightarrow$ $\operatorname{ker} \varphi$ be the restrictions of $h_{1}, l_{1}$, respectively.

We have three possible cases.

Case 1: $g \circ f$ is an isomorphism. In this case,

$$
f: \operatorname{ker} \varphi \rightarrow \operatorname{ker} \varphi^{\prime} \quad \text { and } \quad(g \circ f)^{-1} g: \operatorname{ker} \varphi^{\prime} \rightarrow \operatorname{ker} \varphi
$$

are two morphisms whose composite mapping is the identity. Therefore, $f$ is a splitting monomorphism. As $\operatorname{ker} \varphi$ and $\operatorname{ker} \varphi^{\prime}$ are uniform, $f$ is an isomorphism, so that $\operatorname{ker} \varphi \cong$ $\operatorname{ker} \varphi^{\prime}$. Then $D=\operatorname{ker} \varphi^{\prime \prime}$ has the required properties in this case.

Case 2: $l \circ h$ is an isomorphism. In this case, both $l$ and $h$ are isomorphisms, so that $\operatorname{ker} \varphi \cong \operatorname{ker} \varphi^{\prime \prime}$. Let $D=\operatorname{ker} \varphi^{\prime}$.

Case 3: $g \circ f$ and $l \circ$ h are not isomorphisms. Then $g \circ f$ is not an element in the ideal $I$ of $\operatorname{End}_{R}(\operatorname{ker} \varphi)$. As it is not an invertible element of $\operatorname{End}_{R}(\operatorname{ker} \varphi)$, it follows that $g \circ f \in K$. Similarly, $l \circ h \notin K$, but $l \circ h \in I$. Hence, $g \circ f+l \circ h \notin I \cup K$, and thus, $g \circ f+l \circ h$ is an automorphism of $\operatorname{ker} \varphi$. Then the composite morphism of the morphisms

$$
\operatorname{ker} \varphi \stackrel{\left(\begin{array}{l}
f \\
h
\end{array}\right)}{\longrightarrow} \operatorname{ker} \varphi^{\prime} \oplus \operatorname{ker} \varphi^{\prime \prime} \stackrel{(g \circ f+l \circ h)^{-1}(g, l)}{\longrightarrow} \operatorname{ker} \varphi
$$

is the identity morphism, so that $\operatorname{ker} \varphi \oplus D \cong \operatorname{ker} \varphi^{\prime} \oplus \operatorname{ker} \varphi^{\prime \prime}$ for some module $D$.

(b) Assume $\operatorname{ker} \varphi \oplus D \cong \operatorname{ker} \varphi^{\prime} \oplus \operatorname{ker} \varphi^{\prime \prime} \cong \operatorname{ker} \varphi \oplus D^{\prime}$. By [5, Corollary 4.6], we get that $D \cong D^{\prime}$ because $\operatorname{ker} \varphi$ has a semilocal endomorphism ring. This shows 
that the module $D$ in (a) is unique up to isomorphism. Let us prove that $D$ is the kernel of a non-injective morphism between indecomposable injective modules. The isomorphism $\operatorname{ker} \varphi \oplus D \cong \operatorname{ker} \varphi^{\prime} \oplus \operatorname{ker} \varphi^{\prime \prime}$ extends to an isomorphism $F: E(\operatorname{ker} \varphi) \oplus$ $E(D) \cong E\left(\operatorname{ker} \varphi^{\prime}\right) \oplus E\left(\operatorname{ker} \varphi^{\prime \prime}\right)$, that is, $E_{1} \oplus E(D) \cong E_{1}^{\prime} \oplus E_{1}^{\prime \prime}$. Now $[\operatorname{ker} \varphi]_{m}=\left[\operatorname{ker} \varphi^{\prime}\right]_{m}$ implies $E_{1} \cong E_{1}^{\prime}$. By direct-sum cancellation of modules with semilocal endomorphism rings again, we get that $E(D) \cong E_{1}^{\prime \prime}$. In particular, $D \neq 0$.

The isomorphism $F$ induces an isomorphism

$$
\left(E_{1} / \operatorname{ker} \varphi\right) \oplus(E(D) / D) \cong\left(E_{1}^{\prime} / \operatorname{ker} \varphi^{\prime}\right) \oplus\left(E_{1}^{\prime \prime} / \operatorname{ker} \varphi^{\prime \prime}\right),
$$

so that $E\left(E_{1} / \operatorname{ker} \varphi\right) \oplus E(E(D) / D) \cong E\left(E_{1}^{\prime} / \operatorname{ker} \varphi^{\prime}\right) \oplus E\left(E_{1}^{\prime \prime} / \operatorname{ker} \varphi^{\prime \prime}\right)$. We have already remarked in the first paragraph after the definition of upper part that $[\operatorname{ker} \varphi]_{u}=\left[\operatorname{ker} \varphi^{\prime \prime}\right]_{u}$ implies $E\left(E_{1} / \operatorname{ker} \varphi\right) \cong E\left(E_{1}^{\prime \prime} / \operatorname{ker} \varphi^{\prime \prime}\right)$. By direct-sum cancellation, $E(E(D) / D) \cong E\left(E_{1}^{\prime} / \operatorname{ker} \varphi^{\prime}\right)$. If $\varphi^{\prime}=0$, then $E(E(D) / D)=0$, i.e. $D$ is injective, so that $D=E(D) \cong E_{1}^{\prime \prime}$ is the kernel of the zero mapping $E_{1}^{\prime \prime} \rightarrow E_{1}^{\prime \prime}$. If $\varphi^{\prime} \neq 0$, then $D$ is the kernel of the composite morphism $E(D) \rightarrow E(D) / D \rightarrow E(E(D) / D)$. But $E(D) \cong E_{1}^{\prime \prime}$ and $E(E(D) / D) \cong E\left(E_{1}^{\prime} / \operatorname{ker} \varphi^{\prime}\right) \cong E_{2}^{\prime}$.

(c) We distinguish three possible cases.

Case 1: $D \cong \operatorname{ker} \varphi^{\prime}$. In this case, we have by cancellation from (a) that $\operatorname{ker} \varphi \cong \operatorname{ker} \varphi^{\prime \prime}$. Hence, $[D]_{u}=\left[\operatorname{ker} \varphi^{\prime}\right]_{u}$ and $[D]_{m}=\left[\operatorname{ker} \varphi^{\prime}\right]_{m}=[\operatorname{ker} \varphi]_{m}=\left[\operatorname{ker} \varphi^{\prime \prime}\right]_{m}$.

Case 2: $D \cong \operatorname{ker} \varphi^{\prime \prime}$. In this case, we have by cancellation from (a) that $\operatorname{ker} \varphi \cong \operatorname{ker} \varphi^{\prime}$. Hence, $[D]_{m}=\left[\operatorname{ker} \varphi^{\prime \prime}\right]_{m}$ and $[D]_{u}=\left[\operatorname{ker} \varphi^{\prime \prime}\right]_{u}=[\operatorname{ker} \varphi]_{u}=\left[\operatorname{ker} \varphi^{\prime}\right]_{u}$.

Case 3: $D ¥ \operatorname{ker} \varphi^{\prime}$ and $D ¥ \operatorname{ker} \varphi^{\prime \prime}$. In this case, we can apply Proposition 2.5 to the direct summand $D$ of $\operatorname{ker} \varphi^{\prime} \oplus \operatorname{ker} \varphi^{\prime \prime}$, and get that either (c) holds or $[D]_{m}=\left[\operatorname{ker} \varphi^{\prime}\right]_{m}$ and $[D]_{u}=\left[\operatorname{ker} \varphi^{\prime \prime}\right]_{u}$. But in the second case, $[D]_{m}=[\operatorname{ker} \varphi]_{m}$ and $[D]_{u}=[\operatorname{ker} \varphi]_{u}$, so that $D \cong \operatorname{ker} \varphi$ by Lemma 2.4. Hence, by Proposition 2.5 applied to the direct summands $\operatorname{ker} \varphi^{\prime}$ and $\operatorname{ker} \varphi^{\prime \prime}$ of $\operatorname{ker} \varphi \oplus D$, we get that the four modules $\operatorname{ker} \varphi^{\prime}, \operatorname{ker} \varphi^{\prime \prime}, \operatorname{ker} \varphi, D$ have the same monogeny part and the same upper part. Therefore, $\operatorname{ker} \varphi^{\prime} \cong \operatorname{ker} \varphi^{\prime \prime} \cong$ $\operatorname{ker} \varphi \cong D$, which is a contradiction.

TheOrem 2.7. (Weak Krull-Schmidt theorem) Let $\varphi_{i}: E_{i, 1} \rightarrow E_{i, 2}(i=1,2, \ldots, n)$ and $\varphi_{j}^{\prime}: E_{j, 1}^{\prime} \rightarrow E_{j, 2}^{\prime}(i=1,2, \ldots, t)$ be non-injective morphisms between indecomposable injective modules $E_{i, 1}, E_{i, 2}, E_{j, 1}^{\prime}, E_{j, 2}^{\prime}$ over an arbitrary ring $R$. Then $\oplus_{i=1}^{n} \operatorname{ker} \varphi_{i} \cong$ $\oplus_{j=1}^{t} \operatorname{ker} \varphi_{j}^{\prime}$ if and only if $n=t$ and there exist two permutations $\sigma, \tau$ of $\{1,2, \ldots, n\}$ such that $\left[\operatorname{ker} \varphi_{i}\right]_{m}=\left[\operatorname{ker} \varphi_{\sigma(i)}^{\prime}\right]_{m}$ and $\left[\operatorname{ker} \varphi_{i}\right]_{u}=\left[\operatorname{ker} \varphi_{\tau(i)}^{\prime}\right]_{u}$ for every $i=1,2, \ldots, n$.

Proof. $(\Rightarrow)$ Since the kernels $\operatorname{ker} \varphi_{i}$ and $\operatorname{ker} \varphi_{j}^{\prime}$ are uniform modules, if $\oplus_{i=1}^{n} \operatorname{ker} \varphi_{i} \cong$ $\oplus_{j=1}^{t} \operatorname{ker} \varphi_{j}^{\prime}$, then they have the same Goldie dimension, that is, $n=t$.

For the existence of the permutations $\sigma$ and $\tau$, we use induction on $n$, the case $n=1$ being trivial. Assume that $\operatorname{ker} \varphi_{i}$ is isomorphic to some $\operatorname{ker} \varphi_{j}^{\prime}$. Cancelling the isomorphic modules $\operatorname{ker} \varphi_{i}$ and $\operatorname{ker} \varphi_{j}^{\prime}$ (cancellation of modules holds because they have semilocal endomorphism rings), we can clearly proceed by induction. Therefore, we can suppose that $\operatorname{ker} \varphi_{i} \not \operatorname{ker} \varphi_{j}^{\prime}$ for every $i, j=1,2, \ldots, n$. Note that in this case, the endomorphism rings of $\operatorname{ker} \varphi_{i}, \operatorname{ker} \varphi_{j}^{\prime}$ are not local.

Now $\operatorname{ker} \varphi_{1}$ is isomorphic to a direct summand of $\operatorname{ker} \varphi_{1}^{\prime} \oplus \cdots \oplus \operatorname{ker} \varphi_{n}^{\prime}$. By Proposition 2.5, there exist two distinct indices $i, j=1,2, \ldots, n$ such that $\left[\operatorname{ker} \varphi_{1}\right]_{m}=$ $\left[\operatorname{ker} \varphi_{i}^{\prime}\right]_{m}$ and $\left[\operatorname{ker} \varphi_{1}\right]_{u}=\left[\operatorname{ker} \varphi_{j}^{\prime}\right]_{u}$. For simplicity, we can assume $i=1$ and $j=2$. Now we can proceed as in [2, Theorem 5.3] using Lemma 2.6 instead of [2, Lemma 5.2]. 
3. An example. We now give an example. We will show that if $n \geq 2$ is an integer, then there exist $n^{2}$ pairwise non-isomorphic kernels $\operatorname{ker}\left(\varphi_{i, j}\right)(i, j=1,2, \ldots, n)$ of morphisms $\varphi_{i, j}: E_{i, 1} \rightarrow E_{j, 2}$, where $E_{i, 1}$ and $E_{j, 2}$ are injective indecomposable modules over a suitable serial ring $R$, satisfying the following properties:

(a) For every $i, j, k, \ell=1,2, \ldots, n,\left[\operatorname{ker}\left(\varphi_{i, j}\right)\right]_{m}=\left[\operatorname{ker}\left(\varphi_{k, \ell}\right)\right]_{m}$ if and only if $i=k$.

(b) For every $i, j, k, \ell=1,2, \ldots, n,\left[\operatorname{ker}\left(\varphi_{i, j}\right)\right]_{u}=\left[\operatorname{ker}\left(\varphi_{k, \ell}\right)\right]_{u}$ if and only if $j=\ell$.

Hence,

$$
\begin{aligned}
& \operatorname{ker}\left(\varphi_{1,1}\right) \oplus \operatorname{ker}\left(\varphi_{2,2}\right) \oplus \cdots \oplus \operatorname{ker}\left(\varphi_{n, n}\right) \\
& \quad \cong \operatorname{ker}\left(\varphi_{\sigma(1), \tau(1)}\right) \oplus \operatorname{ker}\left(\varphi_{\sigma(2), \tau(2)}\right) \oplus \cdots \oplus \operatorname{ker}\left(\varphi_{\sigma(n), \tau(n)}\right)
\end{aligned}
$$

for every pair of permutations $\sigma, \tau$ of $\{1,2, \ldots, n\}$.

Here is the example. Let $M_{n}(\mathbb{Q})$ be the ring of all $n \times n$ matrices over the field $\mathbb{Q}$ of rational numbers. Let $\mathbb{Z}$ be the ring of integers and let $\mathbb{Z}_{p}, \mathbb{Z}_{q}$ be the localizations of $\mathbb{Z}$ at two distinct maximal ideals $(p)$ and $(q)$ of $\mathbb{Z}$ (here $p, q \in \mathbb{Z}$ are distinct prime numbers). Let $\Lambda_{p}$ denote the subring of $M_{n}(\mathbb{Q})$ whose elements are the $n \times n$ matrices with entries in $\mathbb{Z}_{p}$ on and above the diagonal and entries in $p \mathbb{Z}_{p}$ under the diagonal, that is,

$$
\Lambda_{p}:=\left(\begin{array}{cccc}
\mathbb{Z}_{p} & \mathbb{Z}_{p} & \cdots & \mathbb{Z}_{p} \\
p \mathbb{Z}_{p} & \mathbb{Z}_{p} & \cdots & \mathbb{Z}_{p} \\
\vdots & & \ddots & \\
p \mathbb{Z}_{p} & p \mathbb{Z}_{p} & \cdots & \mathbb{Z}_{p}
\end{array}\right) \subseteq M_{n}(\mathbb{Q})
$$

Similarly, set

$$
\Lambda_{q}:=\left(\begin{array}{cccc}
\mathbb{Z}_{q} & \mathbb{Z}_{q} & \cdots & \mathbb{Z}_{q} \\
q \mathbb{Z}_{q} & \mathbb{Z}_{q} & \cdots & \mathbb{Z}_{q} \\
\vdots & & \ddots & \\
q \mathbb{Z}_{q} & q \mathbb{Z}_{q} & \cdots & \mathbb{Z}_{q}
\end{array}\right) \subseteq M_{n}(\mathbb{Q})
$$

If

$$
R:=\left(\begin{array}{cc}
\Lambda_{p} & 0 \\
M_{n}(\mathbb{Q}) & \Lambda_{q}
\end{array}\right),
$$

then $R$ is a subring of the ring $M_{2 n}(\mathbb{Q})$ of $2 n \times 2 n$ matrices with rational entries. This ring $R$ appears in an example provided by the first author ([4, Example 2.1], [5, Example 9.20]).

The Jacobson radicals of these rings are

$$
J\left(\Lambda_{p}\right)=\left(\begin{array}{cccc}
p \mathbb{Z}_{p} & \mathbb{Z}_{p} & \cdots & \mathbb{Z}_{p} \\
p \mathbb{Z}_{p} & p \mathbb{Z}_{p} & \cdots & \mathbb{Z}_{p} \\
\vdots & & \ddots & \\
p \mathbb{Z}_{p} & p \mathbb{Z}_{p} & \cdots & p \mathbb{Z}_{p}
\end{array}\right),
$$


and

$$
J(R)=\left(\begin{array}{cc}
J\left(\Lambda_{p}\right) & 0 \\
M_{n}(\mathbb{Q}) & J\left(\Lambda_{q}\right)
\end{array}\right)
$$

For every $i, j=1,2, \ldots, 2 n$, let $e_{i, j}$ be the matrix with 1 in the $(i, j)$ entry and 0 's elsewhere. For simplicity, $e_{i, i}$ will be denoted by $e_{i}$. The set $\left\{e_{1}, \ldots, e_{2 n}\right\}$ is a complete set of orthogonal idempotents for $R$. The left $R$-modules $R e_{i}$ and the right $R$-modules $e_{i} R$ are uniserial. Hence, $R$ is a serial ring. A complete set of representatives of the simple right $R$-modules is given by the $2 n$ modules $e_{i} R / e_{i} J(R), i=1,2, \ldots, 2 n$. For details on the structure of this ring, see [4, Example 2.1] or [5, Example 9.20].

It is well known that, for every divisible abelian group $G$, the right $R$-module $\operatorname{Hom}_{\mathbb{Z}}\left({ }_{R} R, G\right)$ is injective [1, Lemma 18.5]. From the direct-sum decomposition ${ }_{R} R=$ $\oplus_{i=1}^{2 n} R e_{i}$, we get a direct-sum decomposition

$$
\operatorname{Hom}_{\mathbb{Z}}\left({ }_{R} R, G\right)=\oplus_{i=1}^{2 n} \operatorname{Hom}_{\mathbb{Z}}\left(R e_{i}, G\right)
$$

of right $R$-modules. Let $\mathbb{Z}\left(p^{\infty}\right):=\mathbb{Q} / p \mathbb{Z}_{p}$ and $\mathbb{Z}\left(q^{\infty}\right):=\mathbb{Q} / q \mathbb{Z}_{q}$ be the Prüfer groups relative to $p$ and $q$, respectively. Our injective modules will be $E_{i, 1}:=\operatorname{Hom}_{\mathbb{Z}}\left(\operatorname{Re}_{i}, \mathbb{Z}\left(p^{\infty}\right)\right)$ $(i=1, \ldots, n)$ and $E_{j, 2}:=\operatorname{Hom}_{\mathbb{Z}}\left(\operatorname{Re}_{n+j}, \mathbb{Z}\left(q^{\infty}\right)\right)(j=1, \ldots, n)$. If $r \in R$ and $\lambda_{r}: \operatorname{Re}_{i} \rightarrow$ $R e_{i}$ denotes left multiplication by $r$, the right $R$-module structure on $\operatorname{Hom}_{\mathbb{Z}}\left(\operatorname{Re}_{i}, \mathbb{Z}\left(p^{\infty}\right)\right)$ is defined by $\xi r=\xi \circ \lambda_{r}$ for every $\xi \in \operatorname{Hom}_{\mathbb{Z}}\left(R e_{i}, \mathbb{Z}\left(p^{\infty}\right)\right)$.

We claim that $E_{i, 1}$ is the injective envelope of the simple right $R$-module $e_{i} R / e_{i} J(R)$. We have

$$
\operatorname{Re}_{i}=\left(\begin{array}{c}
\mathbb{Z}_{p} \\
\vdots \\
\mathbb{Z}_{p} \\
p \mathbb{Z}_{p} \\
\vdots \\
p \mathbb{Z}_{p} \\
\mathbb{Q}^{n} \\
\vdots \\
\mathbb{Q}
\end{array}\right]_{n}^{n-i}
$$

where we write the elements of $R e_{i}$ as columns (they are $2 n \times 2 n$ matrices, but all the entries that are not in the $i$ th column are zero.) Thus,

$$
E_{i, 1}=(\underbrace{\operatorname{Hom}_{\mathbb{Z}}\left(\mathbb{Z}_{p}, \mathbb{Z}\left(p^{\infty}\right)\right), \ldots}_{i}, \underbrace{\operatorname{Hom}_{\mathbb{Z}}\left(p \mathbb{Z}_{p}, \mathbb{Z}\left(p^{\infty}\right)\right), \ldots}_{n-i}, \underbrace{\operatorname{Hom}_{\mathbb{Z}}\left(\mathbb{Q}, \mathbb{Z}\left(p^{\infty}\right)\right), \ldots}_{n}) .
$$

For every $k=1, \ldots, 2 n$, let $\varepsilon_{k, i}$ be the group morphism defined by

$$
\begin{array}{llll}
\varepsilon_{k, i}: \mathbb{Z}_{p} \rightarrow R e_{i}, & \varepsilon_{k, i}: a \mapsto a e_{k, i}, & \text { for every } a \in \mathbb{Z}_{p}, & \text { for } k=1, \ldots, i, \\
\varepsilon_{k, i}: p \mathbb{Z}_{p} \rightarrow R e_{i}, & \varepsilon_{k, i}: a \mapsto a e_{k, i}, & \text { for every } a \in p \mathbb{Z}_{p}, & \text { for } k=i+1, \ldots, n, \\
\varepsilon_{k, i}: \mathbb{Q} \rightarrow R e_{i}, & \varepsilon_{k, i}: a \mapsto a e_{k, i}, & \text { for every } a \in \mathbb{Q}, & \text { for } k=n+1, \ldots, 2 n .
\end{array}
$$


Let $\pi: \mathbb{Z}_{p} \rightarrow \mathbb{Q} / p \mathbb{Z}_{p}=\mathbb{Z}\left(p^{\infty}\right)$ be the canonical mapping defined by $\pi(a)=a+p \mathbb{Z}_{p}$ for every $a \in \mathbb{Z}_{p}$. Let $\pi_{i}: R e_{i} \rightarrow \mathbb{Z}_{p}$ be the $i$ th canonical projection relative to the direct-sum decomposition (3.1). Consider the element $\sigma=\pi \circ \pi_{i} \in E_{i, 1}$. Its kernel is $J(R) e_{i}$.

In order to prove that $E_{i, 1}$ is the injective envelope of a simple right $R$-module generated by $\sigma$, it suffices to show that for every non-zero element $\xi \in E_{i, 1}$, there exists $r \in R$ with $\xi r=\sigma$. Now if $\xi \in E_{i, 1}$ is non-zero, there exists an index $k=1, \ldots, 2 n$ with $\xi \circ \varepsilon_{k, i}: A \rightarrow \mathbb{Z}\left(p^{\infty}\right)$ non-zero. Here $A=\mathbb{Z}_{p}$ if $k \leq i, A=p \mathbb{Z}_{p}$ if $i<k \leq n$, and $A=\mathbb{Q}$ if $n<k \leq 2 n$. From $\xi \circ \varepsilon_{k, i} \neq 0$, we get that there exists $a \in A$ with $\left(\xi \circ \varepsilon_{k, i}\right)(a)=1+p \mathbb{Z}_{p} \in \mathbb{Q} / p \mathbb{Z}_{p}=\mathbb{Z}\left(p^{\infty}\right)$. Note that $a e_{k, i} \in R$. To prove that $r:=a e_{k, i}$ has the required property, that is, $\xi a e_{k, i}=\sigma$, note that an arbitrary element of $R e_{i}$ is of the form $r=z_{1} e_{1, i}+\cdots+z_{i} e_{i, i}+p z_{i+1} e_{i+1, i}+\cdots+p z_{n} e_{n, i}+\alpha_{1} e_{n+1, i}+\cdots+\alpha_{n} e_{2 n, i}$, and $\left(\xi a e_{k, i}\right)(r)=\xi a z_{i} e_{k, i}=\left(\xi \circ \varepsilon_{k, i}\right)\left(a z_{i}\right)=z_{i}+p \mathbb{Z}_{p}=\sigma(r)$, as desired. This proves that $\xi a e_{k, i}=\sigma$ and shows that $E_{i, 1}$ is the injective envelope of the right $R$-submodule of $E_{i, 1}$ generated by $\sigma$ and that this submodule is simple.

Now consider the mapping $\mu: e_{i} R \rightarrow E_{i, 1}, \mu\left(e_{i} r\right)=\sigma r$. It is well defined, because if $e_{i} r=0$, then $r \in\left(1-e_{i}\right) R$, so that $\sigma r=\pi \circ \pi_{i} \circ \lambda_{r}: R e_{i} \rightarrow \mathbb{Z}\left(p^{\infty}\right)$ is zero because $\pi_{i}\left(\left(1-e_{i}\right) R e_{i}\right)=0$. The image of $\mu$ is the simple module generated by $\sigma$, because $\sigma e_{i}=$ $\sigma$. An element $e_{i} r$ of $e_{i} R$ is in the kernel of $\mu$ if and only if $\sigma e_{i} r=0$, that is, if and only if $\sigma \circ \lambda_{e_{i} r}: R e_{i} \rightarrow \mathbb{Z}\left(p^{\infty}\right)$ is the zero mapping. This happens if and only if $\sigma\left(e_{i} r R e_{i}\right)=0$, that is, if and only if $e_{i} r R e_{i} \subseteq \operatorname{ker} \sigma=J(R) e_{i}$, i.e. if and only if the $(i, i)$ entry of $r$ is in $p \mathbb{Z}_{p}$. Thus, $\operatorname{ker} \mu=e_{i} J(R)$ and $\sigma R \cong e_{i} R / e_{i} J(R)$. This proves that $E_{i, 1}$ is the injective envelope of the simple right $R$-module $e_{i} R / e_{i} J(R)$. Similarly, one shows that $E_{j, 2}$ is the injective envelope of the simple right $R$-module $e_{n+j} R / e_{n+j} J(R)$. Thus, $E_{i, 1}$ and $E_{j, 2}$ $(i, j=1, \ldots, n)$ are $2 n$ injective indecomposable $R$-modules. The matricial description of $E_{j, 2}$ corresponding to (3.2) is

$$
E_{j, 2}=(\underbrace{0, \ldots}_{n}, \underbrace{\operatorname{Hom}_{\mathbb{Z}}\left(\mathbb{Z}_{q}, \mathbb{Z}\left(q^{\infty}\right)\right), \ldots}_{j}, \underbrace{\operatorname{Hom}_{\mathbb{Z}}\left(q \mathbb{Z}_{q}, \mathbb{Z}\left(q^{\infty}\right)\right), \ldots}_{n-j}) .
$$

We are ready to define the $R$-module morphisms $\varphi_{i, j}: E_{i, 1} \rightarrow E_{j, 2}$. Fix once for all a non-zero $\mathbb{Z}$-morphism $f: \operatorname{Hom}_{\mathbb{Z}}\left(\mathbb{Q}, \mathbb{Z}\left(p^{\infty}\right)\right) \rightarrow \mathbb{Z}\left(q^{\infty}\right)$. For every $i, j=1, \ldots, n$, let

$$
\varphi_{i, j}: \operatorname{Hom}_{\mathbb{Z}}\left(R e_{i}, \mathbb{Z}\left(p^{\infty}\right)\right) \rightarrow \operatorname{Hom}_{\mathbb{Z}}\left(R e_{n+j}, \mathbb{Z}\left(q^{\infty}\right)\right)
$$

be the right $R$-module morphism defined by $\varphi_{i, j}(\xi)(r)=f\left(\xi \circ \lambda_{r} \circ \varepsilon_{n+j, i}\right)$ for every $\xi \in$ $\operatorname{Hom}_{\mathbb{Z}}\left(R e_{i}, \mathbb{Z}\left(p^{\infty}\right)\right)$ and every $r \in R e_{n+j}$.

We have to show that the $n^{2}$ kernels $\operatorname{ker} \varphi_{i, j}(i, j=1, \ldots, n)$ have the properties stated at the beginning of this section.

(a) $\Rightarrow)$ Assume $\left[\operatorname{ker}\left(\varphi_{i, j}\right)\right]_{m}=\left[\operatorname{ker}\left(\varphi_{k, \ell}\right)\right]_{m}$. Since every $E_{i, 1}$ is the injective envelope of the simple module $e_{i} R / e_{i} J(R)$, the socle of every $\operatorname{ker}\left(\varphi_{i, j}\right)$ is isomorphic to the simple module $e_{i} R / e_{i} J(R)$. From $\left[\operatorname{ker}\left(\varphi_{i, j}\right)\right]_{m}=\left[\operatorname{ker}\left(\varphi_{k, \ell}\right)\right]_{m}$, it follows that the modules $\operatorname{ker}\left(\varphi_{i, j}\right)$ and $\operatorname{ker}\left(\varphi_{k, \ell}\right)$ must have isomorphic socles, so that $i=k$.

$(\Leftarrow)$ We must show that $\left[\operatorname{ker}\left(\varphi_{i, j}\right)\right]_{m}=\left[\operatorname{ker}\left(\varphi_{i, \ell}\right)\right]_{m}$. Without loss of generality, we may suppose $j \leq \ell$. Note that $\xi$ belongs to $\operatorname{ker} \varphi_{i, j}$ if and only if $\varphi_{i, j}(\xi)=0$, that is, if and only if $\varphi_{i, j}(\xi)\left(R e_{n+j}\right)=0$. Since the elements of $E_{j, 2}$ are not only $\mathbb{Z}$-linear mappings, but also $\mathbb{Z}_{q}$-linear, we have that $\xi \in \operatorname{ker} \varphi_{i, j}$ if and only if $\varphi_{i, j}(\xi)\left(e_{n+1, n+j}\right)=0, \varphi_{i, j}(\xi)\left(e_{n+2, n+j}\right)=0, \ldots, \varphi_{i, j}(\xi)\left(e_{n+j, n+j}\right)=0, \varphi_{i, j}(\xi)\left(q e_{n+j+1, n+j}\right)=$ $0, \ldots, \varphi_{i, j}(\xi)\left(q e_{2 n, n+j}\right)=0$. Now $\varphi_{i, j}(\xi)\left(e_{n+1, n+j}\right)=f\left(\xi \circ \lambda_{e_{n+1, n+j}} \circ \varepsilon_{n+j, i}\right)=f\left(\xi \circ \varepsilon_{n+1, i}\right)$. Thus, $\xi \in \operatorname{ker} \varphi_{i, j}$ if and only if $f\left(\xi \circ \varepsilon_{n+1, i}\right)=0, \ldots, f\left(\xi \circ \varepsilon_{n+j, i}\right)=0, q f\left(\xi \circ \varepsilon_{n+j+1, i}\right)=$ 
$0, q f\left(\xi \circ \varepsilon_{2 n, i}\right)=0$. It is now clear that $j \leq \ell$ implies $\operatorname{ker}\left(\varphi_{i, j}\right) \supseteq \operatorname{ker}\left(\varphi_{i, \ell}\right)$, so that the embedding is a monomorphism $\operatorname{ker}\left(\varphi_{i, \ell}\right) \rightarrow \operatorname{ker}\left(\varphi_{i, j}\right)$. Conversely, multiplication by $q$ is an automorphism of $\mathbb{Z}\left(p^{\infty}\right)$, so that multiplication by $q$ is an automorphism of the $R$ module $E_{i, 1}=\operatorname{Hom}_{\mathbb{Z}}\left(\operatorname{Re}_{i}, \mathbb{Z}\left(p^{\infty}\right)\right)$. Clearly, $q \operatorname{ker}\left(\varphi_{i, j}\right) \subseteq \operatorname{ker}\left(\varphi_{i, \ell}\right)$. Thus, multiplication by $q$ is a monomorphism $\operatorname{ker}\left(\varphi_{i, j}\right) \rightarrow \operatorname{ker}\left(\varphi_{i, \ell}\right)$.

(b) $(\Rightarrow)$ Assume that $i, j, k, \ell=1, \ldots, n$ are indices with $\left[\operatorname{ker}\left(\varphi_{i, j}\right)\right]_{u}=\left[\operatorname{ker}\left(\varphi_{k, \ell}\right)\right]_{u}$. Then, as we have remarked between Lemmas 2.3 and $2.4,\left[E_{i, 1} / \operatorname{ker}\left(\varphi_{i, j}\right)\right]_{m}=$ $\left[E_{k, 1} / \operatorname{ker}\left(\varphi_{k, \ell}\right)\right]_{m}$. So $E_{i, 1} / \operatorname{ker}\left(\varphi_{i, j}\right)$ and $E_{k, 1} / \operatorname{ker}\left(\varphi_{k, \ell}\right)$, which are essential extensions of their simple socles, have isomorphic socles. Hence, $E_{j, 2}$ and $E_{\ell, 2}$ have isomorphic socles, so that $j=\ell$.

$(\Leftarrow)$ We must prove that $\left[\operatorname{ker}\left(\varphi_{i, j}\right)\right]_{u}=\left[\operatorname{ker}\left(\varphi_{k, j}\right)\right]_{u}$ for every $i, j, k=1, \ldots, n$. We can suppose $i<k$. Right multiplication by the element $e_{i, k}$ of $R$ is a left $R$-module morphism $\rho_{e_{i, k}}: R e_{i} \rightarrow R e_{k}$, which induces a morphism $\operatorname{Hom}_{\mathbb{Z}}\left(\rho_{e_{i, k}}, \mathbb{Z}\left(p^{\infty}\right)\right): E_{k, 1}=$ $\operatorname{Hom}_{\mathbb{Z}}\left(R e_{k}, \mathbb{Z}\left(p^{\infty}\right)\right) \rightarrow E_{i, 1}:=\operatorname{Hom}_{\mathbb{Z}}\left(R e_{i}, \mathbb{Z}\left(p^{\infty}\right)\right)$. We have a diagram of right $R$ module morphisms

$$
\begin{array}{rccc}
E_{k, 1} & \stackrel{\varphi_{k, j}}{\longrightarrow} & E_{j, 2} \\
\operatorname{Hom}_{\mathbb{Z}\left(\rho_{e_{i, k}}, \mathbb{Z}\left(p^{\infty}\right)\right) \downarrow} & & \downarrow \\
E_{i, 1} & \stackrel{\varphi_{i, j}}{\longrightarrow} & E_{j, 2},
\end{array}
$$

in which the vertical arrow on the right denotes the identity. The diagram is commutative, because for every $s \in E_{k, 1}$ and every $r \in R e_{n+j}$, one has that $\left(\varphi_{i, j} \circ \operatorname{Hom}_{\mathbb{Z}}\left(\rho_{e_{i, k}}, \mathbb{Z}\left(p^{\infty}\right)\right)\right)(s)(r)=\left(\varphi_{i, j}\left(s \circ \rho_{e_{i, k}}\right)\right)(r)=f\left(s \circ \rho_{e_{i, k}} \circ \lambda_{r} \circ \varepsilon_{n+j, i}\right)=f(s \circ$ $\left.\lambda_{r} \circ \varepsilon_{n+j, k}\right)=\varphi_{k, j}(s)(r)$.

Similarly, right multiplication by the element $p e_{k, i}$ of $R$ is a left $R$-module morphism $\rho_{p e_{k, i}}: R e_{k} \rightarrow R e_{i}$, which induces a right $R$-module morphism $\operatorname{Hom}_{\mathbb{Z}}\left(\rho_{p e_{k, i}}, \mathbb{Z}\left(p^{\infty}\right)\right)$ : $E_{i, 1}=\operatorname{Hom}_{\mathbb{Z}}\left(R e_{i}, \mathbb{Z}\left(p^{\infty}\right)\right) \rightarrow E_{k, 1}:=\operatorname{Hom}_{\mathbb{Z}}\left(R e_{k}, \mathbb{Z}\left(p^{\infty}\right)\right)$. Hence, we have a second commutative diagram

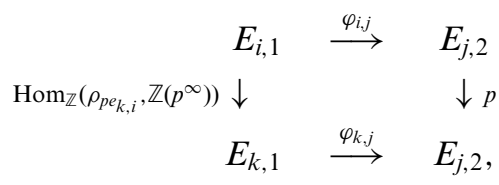

in which the vertical arrow on the right denotes the automorphism of $E_{j, 2}$ given by multiplication by $p$. The two commutative diagrams (3.3) and (3.4) show that $\left[\operatorname{ker}\left(\varphi_{i, j}\right)\right]_{u}=\left[\operatorname{ker}\left(\varphi_{k, j}\right)\right]_{u}$. This concludes all the verifications in our example.

4. Duality. Let $E_{R}$ be a fixed indecomposable injective module over an arbitrary $\operatorname{ring} R$ and $S=\operatorname{End}\left(E_{R}\right)$ be its endomorphism ring. Then $S$ is a local ring and ${ }_{S} E_{R}$ is a bimodule. For every fixed non-zero endomorphism $f \in S$, we have an exact sequence of cyclic left $S$-modules

$$
{ }_{S} S \stackrel{f}{\longrightarrow} S S \longrightarrow S / S f \longrightarrow 0 .
$$

Here the first arrow denotes the endomorphism of ${ }_{S} S$ given by right multiplication by $f$. If we apply the left exact functor $\operatorname{Hom}\left(-,{ }_{S} E_{R}\right): S$-Mod $\rightarrow \operatorname{Mod}-R$ to the exact 
sequence (4.1), we obtain an exact sequence of right $R$-modules

$$
0 \longrightarrow \operatorname{Hom}\left(S / S f,{ }_{S} E\right) \longrightarrow \operatorname{Hom}\left({ }_{S} S,{ }_{S} E\right) \stackrel{\operatorname{Hom}\left(f,{ }_{s} E\right)}{\longrightarrow} \operatorname{Hom}\left({ }_{S} S,{ }_{S} E\right)
$$

Note that $\operatorname{Hom}\left({ }_{S} S,{ }_{S} E\right)$ is canonically isomorphic to $E_{R}$ as a right $R$-module, and via this isomorphism the endomorphism $\operatorname{Hom}\left(f,{ }_{S} E\right)$ of $\operatorname{Hom}\left({ }_{S} S,{ }_{S} E\right)$ becomes the right $R$-module endomorphism $f$ of $E_{R}$. Hence, (4.2) becomes the exact sequence

$$
0 \longrightarrow \operatorname{ker} f \longrightarrow E_{R} \stackrel{f}{\longrightarrow} E_{R} .
$$

Thus, the projective presentation (4.1) of a cyclically presented left module over the local ring $S$ becomes an injective co-presentation of the kernel of a morphism between two injective indecomposable modules both isomorphic to $E_{R}$.

Proposition 4.1. Let $E_{R}$ be an indecomposable injective module and $S=\operatorname{End}\left(E_{R}\right)$ its endomorphism ring. Let $f, g$ be non-zero elements of $S$. Then, the following hold:

(a) $[S / S f]_{e}=[S / S g]_{e}$ if and only if $[\operatorname{ker} f]_{m}=[\operatorname{ker} g]_{m}$.

(b) $[S / S f]_{l}=[S / S g]_{l}$ if and only if $[\operatorname{ker} f]_{u}=[\operatorname{ker} g]_{u}$.

Proof. (a) Assume $[S / S f]_{e}=[S / S g]_{e}$. Then there exist $s, t \in S$ and $u, v \in U(S)=$ $\operatorname{Aut}\left(E_{R}\right)$ with $s f=g u$ and $t g=f v$. Hence, we have the following commutative diagrams:

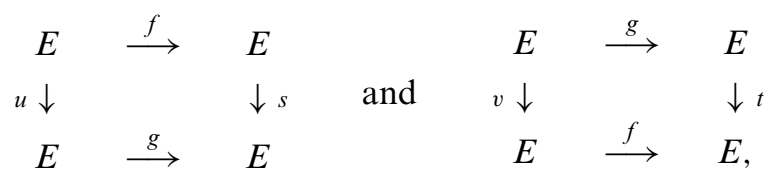

in which the two vertical arrows $u, v$ on the left are automorphisms. From the commutativity of the diagrams, it is easily seen that $u(\operatorname{ker} f) \subseteq \operatorname{ker} g$ and $v(\operatorname{ker} g) \subseteq$ $\operatorname{ker} f$. Thus, the restrictions of the automorphisms $u$ and $v$ show that $[\operatorname{ker} f]_{m}=[\operatorname{ker} g]_{m}$.

Conversely, assume that $[\operatorname{ker} f]_{m}=[\operatorname{ker} g]_{m}$. Then there exist monomorphisms $u^{\prime}: \operatorname{ker} f \rightarrow \operatorname{ker} g$ and $v^{\prime}: \operatorname{ker} g \rightarrow \operatorname{ker} f$, which extend to automorphisms $u: E \rightarrow E$ and $v: E \rightarrow E$ such that $u(\operatorname{ker} f) \subseteq \operatorname{ker} g$ and $v(\operatorname{ker} g) \subseteq \operatorname{ker} f$. These automorphisms induce homomorphisms $\tilde{u}: E / \operatorname{ker} f \rightarrow E / \operatorname{ker} g$ and $\widetilde{v}: E / \operatorname{ker} g \rightarrow E / \operatorname{ker} f$, which extend to two endomorphism $s, t$ of $E$. We have a commutative diagram

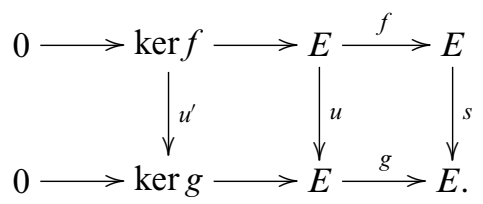

Thus, $s \in S, u \in U(S)$ and $s f=g u$. Similarly, one proves that $t g=f v$.

(b) Suppose $[S / S f]_{l}=[S / S g]_{l}$. Then there exist $\alpha, \beta \in U(S)$ and $s, t \in S$ that make the following diagrams commute:

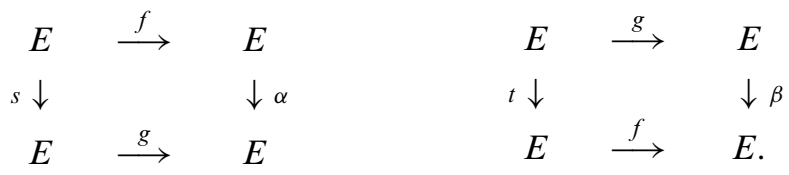


To prove that $[\operatorname{ker} f]_{u}=[\operatorname{ker} g]_{u}$, it suffices to show that $s^{-1}(\operatorname{ker} g)=\operatorname{ker} f$ and $t^{-1}(\operatorname{ker} f)=\operatorname{ker} g$. Now if $x \in E$ and $s(x) \in \operatorname{ker} g$, then $\alpha f(x)=g s(x)=0$, so that $f(x)=0$, that is, $x \in \operatorname{ker} f$. This proves that $s^{-1}(\operatorname{ker} g) \subseteq \operatorname{ker} f$. Conversely, assume $x \in$ $\operatorname{ker} f$. Then $g s(x)=\alpha f(x)=0$. Hence, $s^{-1}(\operatorname{ker} g)=\operatorname{ker} f$. Similarly, $t^{-1}(\operatorname{ker} f)=\operatorname{ker} g$.

Conversely, assume $[\operatorname{ker} f]_{u}=[\operatorname{ker} g]_{u}$. Then there exist $\alpha, \beta \in U(S)$ and $s, t \in S$, which make diagrams (4.3) commute, that is, such that $\alpha f=g s$ and $\beta g=f t$. It follows that $[S / S f]_{l}=[S / S g]_{l}$.

\section{REFERENCES}

1. F. W. Anderson and K. R. Fuller, Rings and categories of modules, 2nd edn., GTM, vol. 13 (Springer-Verlag, New York, 1992).

2. B. Amini, A. Amini and A. Facchini, Equivalence of diagonal matrices over local rings, J. Algebra 320 (2008), 1288-1310.

3. R. T. Bumby, Modules which are isomorphic to submodules of each other, Arch. Math. 16 (1965), 184-185.

4. A. Facchini, Krull-Schmidt fails for serial modules, Trans. Amer. Math. Soc. 348 (1996), 4561-4575.

5. A. Facchini, Module theory. Endomorphism rings and direct sum decompositions in some classes of modules, Progress in Mathematics, vol. 167 (Birkhäuser Verlag, Basel, Switzerland, 1998).

6. A. Facchini and D. Herbera, Local morphisms and modules with a semilocal endomorphism ring, Algebr. Represent. Theory 9 (2006), 403-422.

7. D. T. Gill, Almost maximal valuation rings, J. Lond. Math. Soc. 4(2) (1971), 140-146.

8. E. Matlis, Injective modules over Noetherian rings, Pacific J. Math. 8 (1958), 511-528.

9. T. S. Shores and J. W. Lewis, Serial modules and endomorphism rings, Duke Math. J. 41 (1974), 889-909. 